\title{
A construção dos ethé de credibilidade e de identificação: análise do discurso político do presidente da Guiné-Bissau José Mário Vaz
}

\author{
Jeremias Demba (UNILAB)* \\ https://orcid.org/0000-0002-0896-4037 \\ Alisson Fernando Abreu de Sousa (UNILAB)** \\ https://orcid.org/0000-0002-5926-3521 \\ Kennedy Cabral Nobre (UNILAB)*** \\ https://orcid.org/0000-0002-8382-2151
}

\section{Resumo:}

Este trabalho tem como foco principal analisar a construção dos ethé de credibilidade e de identificação do presidente da República da Guiné-Bissau José Mário Vaz, numa mensagem à nação e aos parlamentares sobre a então situação de tensão política entre os órgãos de soberania governamental, pronunciada em 2015. Para realizar tal intento, a metodologia baseia-se numa interpretação qualitativa dos dados, levando em consideração as concepções de ethos discursivo em Amossy (2013) e em Maingueneau (2008, 2013, 2018, 2020), e os postulados teóricos de Charaudeau (2015) sobre os ethé de credibilidade e de identificação. Os resultados indicam que há uma alternância na construção dos ethé do presidente José Mário Vaz, em decorrência do contexto sociopolítico de instabilidade política.

Palavras-chave: Ethos; Discurso político; José Mário Vaz; Guiné-Bissau.

\section{Abstract:}

\section{The construction of the credibility and identification ethé: analysis of the political speech Guinea-Bissau president José Mário Vaz}

This work has as main focus to analyze the construction of ethé of credibility and identification of the President of the Republic of Guinea-Bissau José

* Mestrando do Programa de Pós-Graduação em Estudos da Linguagem (PPGLIN) da Universidade da Integração Internacional da Lusofonia Afro-Brasileira (UNILAB), bolsista da Fundação Cearense de Apoio ao Desenvolvimento Científico e Tecnológico (FUNCAP). E-mail: jeredemba29@gmail.com

** Mestre em Estudos da Linguagem pela Universidade da Integração Internacional da Lusofonia Afro-Brasileira (UNILAB). E-mail: alissonabreu7@gmail.com

*** Professor Doutor do Programa de Pós-Graduação em Estudos da Linguagem (PPGLIN) da Universidade da Integração Internacional da Lusofonia Afro-Brasileira (UNILAB). E-mail: cabralnobre@unilab.edu.br 


\begin{abstract}
Mário Vaz, in a message to the nation and the parliamentarians about the situation of political tension between the organs of governmental sovereignty, pronounced in 2015. To achieve this goal, the methodology is based on a qualitative interpretation of the data, taking into account the conceptions of discursive ethos in Amossy (2013) and Maingueneau (2008, 2013, 2018, 2020), and the theoretical postulates of Charaudeau (2015) on the ethé of credibility and identification. The results indicate that there is an alternation in the construction of the ethé of President José Mário Vaz, due to the socio-political context of political instability.
\end{abstract}

Keywords: Ethos; Political speech; José Mario Vaz; Guinea-Bissau.

\section{Introdução}

0 ethos retórico é uma categoria constitutiva da persuasão, pois refere-se aos traços de caráter do orador, isto é, às imagens de si veiculadas no e por meio do discurso. Aristóteles (2005) defende que há mais eficácia argumentativa quando o orador, no discurso, busca mostrar-se como prudente, simples, sincero, virtuoso e amável, do que o contrário disso. Já na contemporaneidade, a Análise do Discurso (AD), um campo de pesquisa fundamentalmente transdisciplinar "[...] no qual as hibridações conceituais se multiplicam" (MAINGUENEAU, 2015, p. 11), vem realizando pesquisas sobre o ethos discursivo, considerando a noção adâmica aristotélica, mas ultrapassando-a em termos teórico-metodológicos.

É no quadro epistemológico da $\mathrm{AD}$ que nosso trabalho se desenvolve, na medida em que objetivamos analisar a construção dos ethé de credibilidade e de identificação (cf. CHARAUDEAU, 2015) do presidente guineense José Mário Vaz (conhecido também por Jomav), em mensagem à nação e aos parlamentares que integram a Assembleia Nacional Popular (ANP) sobre a então situação de tensão política entre os órgãos de soberania governamental, pronunciada no ano de 2015. Para realizar tal intento, buscamos observar as condições de produção do discurso, a situação de enunciação em que o orador se encontra, a representação coletiva e prévia que o público tem a respeito do presidente, bem como os elementos linguísticos que compõem a materialidade do discurso.

Essa proposta de análise surge do questionamento de como o presidente da República de Guiné-Bissau constrói determinados tipos de ethé, considerando o contexto político guineense marcado por crises sociais e humanitárias, por instabilidade governativa, por pressões externas e pela desconfiança dos cidadãos em seus representantes políticos.

Outrossim, podemos dizer que o ethos é uma das categorias que constitui o discurso político. Por essa razão, tal relação é tema geral de uma série de estudos que foram desenvolvidos sob o escopo da $\mathrm{AD}$, dentre os quais destacamos os de Arcine e Passetti (2010), de Mesti (2010), de Ferrante (2011), de Pita e Pinto (2014), de Gandin e Panke (2015), e de Tomaz e Gouvêa (2017).

A pesquisa de Arcine e Passetti (2010) discorre sobre o ethos de identificação no discurso do então candidato à presidência da República Federativa do Brasil, José Serra (PSDB). A partir da tipologia dos ethé de credibilidade e de identificação proposta por Charaudeau, as autoras procuraram compreender como foram construídos os ethé 
de identificação, e como contribuíram para a criação de afetividade/identificação dos eleitorados para com o candidato tucano no processo eleitoral de 2010. Com isso, o trabalho concluiu que os ethé de identificação, principalmente, os de humanidade e de solidariedade permitem que o candidato crie um vínculo afetuoso, de proximidade, para com os eleitores, com o fito de conduzi-los a aderirem aos seus ideais, e a votarem nele.

Ainda em discursos de campanhas eleitorais, Mesti (2010) versou sobre a constituição dos ethé nos discursos de Silvio Barros (MDB), candidato à prefeitura de Maringá-PR, respectivamente, em 2004 e 2008. A partir da análise, compreendeu-se a importância de se observar as condições de produção dos discursos político, uma vez que determinam as escolhas linguísticas e discursivas para a construção dos ethé. A pesquisa constatou que, em 2004, período em que o candidato lançou sua candidatura, pela necessidade de aproximação e de divulgação de si próprio (seus ideais, comportamento e posicionamento político etc.) aos telespectadores/eleitores, ele constrói, predominantemente, os ethé de identificação; já em 2008, ele buscou construir os ethé de credibilidade no intuito de comprovar sua competência, já que disputava a reeleição.

Já Ferrante (2011) busca analisar o ethos nos discursos de posse do prefeito de São Caetano de Sul, respectivamente, nos dias $1^{\circ}$ de janeiro de 2005 e de 2009. A sua pesquisa desvela que as imagens variam a partir da situação em que o político está inserido. Em 2005, início de seu primeiro mandato, há uma predominância de ethé de identificação em seu discurso de posse. Em 2009, segundo mandato do prefeito, o discurso de posse é marcado por uma imagem que projeta confiança e que está consolidada para com a instância cidadã.
Por seu lado, Pita e Pinto (2014) consideram que não apenas a materialidade textual interfere na construção de ethé textuais, mas também a cultura de cada país, ao compararem mensagens de final de ano dos estadistas de Portugal e do Brasil nos anos 2011 e 2012, Pedro Passos Coelho e Dilma Rousseff, respectivamente. 0 trabalho mostra a possibilidade analítica de considerar, majoritariamente, elementos do texto para veiculação de imagens de si. Assim, foi possível constatar ethé diferentes e semelhantes de cada estadista, seja pela escolha lexical própria das variedades linguísticas, seja ainda pelos contextos sócio-históricos de cada país. As autoras defendem que essas construções estão relacionadas a própria essência, intrínseca em cada cultura.

Gandin e Panke (2015) procuraram analisar, em seu trabalho, de que modo ocorre a transferência dos ethé do ex-presidente Luís Inácio Lula da Silva (PT) para as imagens atribuídas a Dilma Viana Rousseff (PT), no Horário Gratuito de Propaganda Eleitoral na televisão (HGPE), no período de campanha eleitoral de 2010. Concluiu-se que os ethé de Dilma estão amparados nos de Lula, uma vez que as imagens de herói, líder e pai (representativas de Lula) são atribuídas a Dilma sob as imagens de guerreira, gestora e mãe. Além disso, foi possível constatar que os ethé de identificação de Lula assim como os de Dilma oscilam concomitantemente. No que tange aos ethé de credibilidade, notou-se o movimento contrário, haja vista que tais imagens estão realçadas em Dilma, e em Lula estão estabilizadas ou decrescem.

Por fim, Tomaz e Gouvêa (2017) analisam o modo como Luís Inácio Lula da Silva utiliza determinadas estratégias discursivas para a construção de um ethos popular, em 11 discursos não oficiais pronunciados no decorrer de seus dois mandatos presiden- 
ciais (2002-2010). Depois da análise, observou-se que Lula constrói para si o ethos popular, principalmente porque, em sua fala, ele se vale de metáforas para explicar estratégias políticas complexas à população. Também constatou-se que há uma predominância dos ethé de identificação em relação aos de credibilidade, especialmente o ethos de chefe popular, tendo em vista que o presidente demonstra estar próximo do povo, que leva em consideração a opinião popular nas decisões políticas.

É possível notar, assim, que existe uma literatura vasta a respeito do ethos discursivo e de sua relação intrínseca com o discurso político. No entanto, nenhuma pesquisa que selecionamos aqui procurou verificar a projeção de imagens de si de um presidente guineense inserido em um contexto político conflituoso. Nos portais dos periódicos CAPES e da Biblioteca Digital de Teses e Dissertações (BDTD), não encontramos nenhum trabalho que discorra sobre a temática proposta em nosso artigo. Nesse sentido, consideramos que o nosso estudo, por seu pioneirismo, justifica-se por duas razões: (i) insere-se em um escopo teórico-metodológico já consolidado, o da $\mathrm{AD}$, a qual fornece noções basilares e um modelo de análise de ethé no discurso político (cf. CHARAUDEAU, 2015); (ii) reflete sobre fatos sociopolíticos específicos da Guiné-Bissau que influenciam na construção de imagens de si do presidente guineense.

\section{Breves considerações sobre o contexto histórico-político de Guiné-Bissau (GB)}

A República da Guiné-Bissau, segundo Araújo (2012), é regida por uma forma de governo democrático e laico, com um regime semipresidencialista, de pendor parlamentar.
No entanto, esse país apresenta uma história política instável desde a sua independência, ocorrida em 1973, fato que ainda inviabiliza o desenvolvimento e a estabilidade política almejados pelo povo. Esse país da costa do ocidente africano, assim como a maioria dos países africanos, enfrentou um doloroso processo de invasão e colonização europeia, que deixou marcas pungentes tanto na cultura, como na política e na história da população guineense (AUGEL, 2007; M'BUNDE, 2018).

Na luta (armada e política) pela independência, surgiram movimentos e partidos pan-africanistas cujo objetivo era libertar Guiné-Bissau e outros países africanos do colonialismo lusitano, como por exemplo, o Movimento Independentista da Guiné-Bissau (MIGB), um dos mais importantes nessa empreitada. M'bunde (2018) destaca que o MIGB não tinha como pauta a conquista da independência por via armada, mas pelo diálogo; este foi inviável devido à falta de interesse dos colonizadores portugueses, junto a organizações internacionais, como a ONU (Organização das Nações Unidas) e a OUA (Organização da Unidade Africana). 0 autor fala do massacre dos trabalhadores de Pindjikiti, ocorrido em agosto de 1959, como um exemplo da rejeição dos colonizadores para estabelecer meios pacíficos de negociações com a população guineense.

Já o Partido Africano para a Independência de Guiné e Cabo-verde (PAIGC), uma das forças políticas mais influente na GuinéBissau atualmente, optou pela luta armada. Embora houvesse uma intenção comum de independência, tem-se muitos registros de conflitos entre os próprios países africanos. Por exemplo, Amílcar Lopes Cabral, pan-africanista e líder do PAIGC, foi morto em decorrência das divergências vigentes 
entre líderes cabo-verdianos e guineenses. Por algum tempo, a mando dos colonizadores, a Guiné-Bissau foi administrativamente dominada por assimilados cabo-verdianos, para "manter a ordem colonial" e repreender os "rebeldes" não assimilados/autóctones/indígenas. Este fato desencadeou um desconforto entre a população e é considerado como uma das principais razões da ruptura entre os dois países (M'BUNDE, 2018).

Após a proclamação da independência de Guiné-Bissau, foi eleito, de modo indireto, o seu primeiro presidente guineense, Luís Lopes Cabral, um dos combatentes durante a Guerra de Libertação e irmão de Amílcar Cabral. Seu mandato, de 1974 a 1980, "foi marcado por muita instabilidade e uma série de assassinatos de líderes antes irmanados na luta" (AUGEL, 2007, p. 63). Durante esse período, embora não tenha declarado explicitamente, o PAIGC defendia o modelo socialista como programa político, com vista a preservar os laços construídos com os países socialistas da extinta União Soviética, que o apoiou durante o processo de luta de libertação nacional, e como uma forma de sair da crise que assolava os países subsaarianos.

Em consequência disso, Luís Cabral sofreu um golpe do Movimento Reajustador (MR) liderado pelo seu primeiro ministro, João Bernardo Vieira (Nino Viera), em 14 de Novembro de 1980. 0 referido golpe culminou com a ruptura entre Guiné-Bissau e Cabo-Verde, e com a ascensão de Nino à presidência. Durante seu mandato, houve graves tensões de cunho tribal, resultando no encarceramento e na morte de alguns líderes políticos.

O mandato de Nino Vieira também foi marcado por problemas político-econômi$\cos$, que resultaram em um golpe militar e numa guerra civil, em junho 1998. Esses conflitos duraram onze meses e foram marcados pelo autoritarismo, por abusos de poder, por uma ditadura regida à mão-deferro pelo PAIGC, "[...] Partido-Estado, partido único, força onipresente e onipotente, auto-intitulado representante da democracia revolucionária, coberto e legítimo pelas glórias da libertação" (AUGEL, 2007, p. 63).

O PAIGC passou a controlar toda vida social política, econômica e cultural do país, instituído no artigo 4o da Constituição da República de 1973, que definia o PAIGC como a única força política e o dirigente máximo da sociedade, do estado e de toda a nação (TEIXEIRA, 2015, p. 2004).

Nesse sentido, nota-se uma contradição política instaurada na Guiné-Bissau pós-independente, uma vez que o PAIGC, outrora movimento libertador, serviu como mantenedor de uma política ditatorial sob o pretexto constitucional. Esse fato atrasou ainda mais o desenvolvimento econômico do país e agravou a instabilidade política.

De acordo com M'bunde (2018), o multipartidarismo só foi implementado em 1991, ano de abertura democrática e constitucional, com a organização das primeiras eleições multipartidárias, as quais contaram com a participação de muitos partidos de cunho democrático que fizeram oposição ao PAIGC, tais como a Aliança Democrática (AD), o Partido Social Democrata (PSD), a Frente Democrática Social (FDS), a União Nacional para a Democracia e o Progresso (UNDP), o RGB/Movimento Bafatá, o Partido da Renovação Social (PRS), e a União para Mudança (UM).

A Guiné-Bissau, desde a sua independência até hoje é marcada por acontecimentos que causaram inúmeras crises políticas, sociais e culturais, tais como golpes de estado que impediram presidentes e primeiros- 
ministros de concluírem seus mandatos ${ }^{1}$, tentativas de assaltos, assassinatos contra a presidência, perseguições políticas.

Todos esses problemas são vistos como disputa de poder entre atores políticos: muitas vezes um político não consegue se eleger democraticamente, então busca meios ilícitos ou recorre às Forças Armadas para conseguir uma aliança militar. Isso vem ocasionando ao longo deste regime "democrático" constante instabilidade política no país (IÉ; LANGA, 2019, p. 4).

Nas eleições de 2014, José Mário Vaz elegeu-se o presidente da nação, sendo o primeiro a concluir o ciclo presidencial, em 2019. Mesmo assim, seu governo passou por diversas crises e tensões políticas; após o término de sua função política, Jomav continuou a exercer seu cargo, anda que de modo inconstitucional; ele também foi acusado de bloquear a ação dos chefes de estado que nomeou para seu governo; demitiu Domingos Simão Pereira, então primeiro-ministro e presidente do PAIGC, acusando-o de corrupção e nepotismo, fato que ocasionou $o$ fechamento do parlamento do país e que foi condenada pela Comunidade Internacional (cf. IÉ; LANGA, 2019).

Assim, podemos compreender que a instabilidade governativa vivenciada na GuinéBissau antes e após a sua independência, inclusive a partir do momento em que aderiu ao sistema multipartidarista e democrático, é um fator que impede o desenvolvimento do país em setores estratégicos da sociedade (saúde, educação, economia, política, segurança). Uma das razões dessa realidade política é o fato de que, desde a independên-

1 Os golpes correram, respectivamente, nos anos 1980, 1998, 2003, 2009 e 2012. De 1973 a 2014 nenhum presidente nem primeiro-ministro eleitos democraticamente conseguiram completar os seus ciclos de mandatos, tendo em conta a recorrente instabilidade política no país (IÉ; LANGA, 2019). cia de Guiné-Bissau, somente um governo eleito democraticamente conseguiu terminar o mandato, conforme previsto na Constituição da República, ainda que repleto de problemas. Não é dubitável que o discurso político, durante todo esse período tenha desempenhado um papel muito importante. Nota-se que, em Guiné-Bissau (e em outros países africanos), a independência não implicou imediatamente uma forma de governo democrático, mesmo quando os políticos guineenses passaram a ser eleitos democraticamente.

\section{0 conceito de ethos}

Como já dito anteriormente, o ethos remonta à Retórica aristotélica, conceituado como imprescindível na construção da persuasão, uma vez que diz respeito à construção dos traços de caráter daquele que fala, "[...] pouco importando a sua sinceridade" (BARTHES, 1985, p. 119). Para Aristóteles (2005), o ethos estabelece relação com o pathos (relacionado ao auditório) e com o logos (relacionado ao discurso, à eloquência), formando a tríade que colabora no exercício de influência e de persuasão sobre o público. Assim, considerando-se que transmitir uma boa impressão de si no ato discursivo é uma estratégia producente na argumentação, o ethos é um elemento crucial no discurso político.

Sob uma perspectiva eminentemente discursiva, Amossy (2013) elucida que todo ato de linguagem pressupõe uma construção da imagem de si, em que se deve considerar também os dados pré-discursivos, isto é, os estereótipos coletivos e as representações que o público faz do sujeito falante antes que ele tome a palavra, tais como a sua categoria social, profissional e institucional, a sua vida pública e familiar, a sua posição política e ideológica, o seu posicionamento 
perante temas controversos, entre outros. É por meio dessa interação discursiva que o ethos é constituído, já que essas circunstâncias condicionam as maneiras de dizer e de ser, passíveis de serem identificadas pelas marcas linguísticas, e pela situação de enunciação.

Nessa mesma linha, Maingueneau (2008) concebe o ethos a partir de uma noção tríplice que integra (i) elementos do discurso, da sua materialidade; (ii) da interação, da influência sobre o outro; (iii) e da situação comunicativa e suas condições sócio-históricas de produção.

Maingueneau (2011) argumenta também que, por meio da enunciação, é possível revelar algumas características do enunciador, como a sua personalidade, por exemplo. Para ele, a imagem do enunciador (fiador) engloba não só os traços da fala (voz, tom), mas inclui os valores psíquicos (caráter) e os traços da corporalidade (físico). Dessa forma, o enunciador procura encarnar em si próprio o que diz, permitindo uma adesão a partir do imaginário do co-enunciador, que incorpora as imagens produzidas.

É por essa razão que Maingueneau (2013) afirma que o ethos discursivo está ligado ao ato de enunciação. Ressalte-se que, para compreendermos o ethos, é preciso considerar, ao mesmo tempo, aquilo que é dito e o que é mostrado, justamente porque "[...] o ethos discursivo mostra-se no ato de enunciação, não é dito no enunciado" (MAINGUENEAU, 2018, p. 323). Ou seja, a noção de ethos que defendemos não é pré-estabelecida somente pela forma e no que se diz; é também uma maneira de ser que influencia o outro, que não pode ser compreendido fora de uma situação comunicativa e de suas condições sócio-históricas de produção.

No que tange ao ethos no âmbito político, Charaudeau (2015) corrobora com a visão de que a construção do ethos apoia-se em dados anteriores ao ato de fala, o que implica que há um ethos prévio (ou pré-discursivo). Ou seja, o ethos discursivo constrói-se a partir da relação entre o dito e o mostrado, apoiando-se em dados preexistentes. Para o autor, a projeção de imagens de si depende também dos entrelaçamentos entre as instâncias política, cidadã e midiática que compõem o dispositivo político. A primeira instância é responsável pela organização da sociedade, figurando-se como entidade que exerce o poder, tendo como função as resoluções dos problemas sociais; a segunda é responsável pela legitimação da instância política através de rituais, como a eleição, o que implica que ela detém certo poder; e a terceira figura entre a cidadã e a política (é intermediária, portanto), assumindo o compromisso de disseminar a informação, e questionar algumas práticas sociais e políticas.

Ademais, o ethos atrela-se ao imaginário de valores sociais, morais e éticos, pelos quais os políticos podem criar imagens de si, ora com o intuito de mostrar-se como digno de crédito, isto é, como pessoa que tem legitimidade e credibilidade para agir de determinada forma, haja vista que "[...] a credibilidade repousa sobre o um poder fazer, e mostrar-se crível é mostrar ou apresentar a prova de que se tem esse poder" (CHARAUDEAU, 2015, p. 119); ora com a finalidade de buscar uma identificação para com os cidadãos, que, "mediante um processo de identificação irracional, fundam sua identidade na do político" (op. cit., p. 137).

Assim, a situação de enunciação na qual o político se encontra (de continuidade de governo, de crise, sob ataque de críticas, pressão política etc.) determina o modo pelo qual ele pode construir para si imagens de credibilidade e de identificação. 
Toda construção do ethos se faz em uma relação triangular entre si, o outro e um terceiro ausente, portador de uma imagem ideal de referência: o si procura endossar essa imagem ideal; o outro se deixa levar por um comportamento de adesão à pessoa que ele se dirige por intermédio dessa mesma imagem ideal de referência. É assim com os ethé de credibilidade, e também com os de identificação (CHARAUDEAU, 2015, p. 137).

Nesse sentido, Charaudeau (2015) divide os diversos ethé em duas grandes categorias, a saber, as de credibilidade, subdivididas em ethos de "sério", de "virtude" e de "competência"; e as de identificação, subdivididas em ethos de "potência", de "caráter", de "inteligência", de "humanidade", de "chefe" e de "solidariedade".

\subsection{Ethé de credibilidade}

o ethos de "sério" pode ser construído pelo sujeito político quando ele demonstra rigidez corporal; não sorri em qualquer circunstância nem brinca; tem autocontrole diante das críticas; diz estar presente em todas as linhas de frente políticas e sociais; não desvela frivolidade; faz declarações a respeito de si próprio; suas propostas exprimem justa medida; recusa a demagogia; preocupa-se com o bem público de maneira realista. Essa imagem é projetada também quando ele atende a condição de sinceridade, isto é, tem coerência daquilo que diz com o que pensa (CHARAUDEAU, 2015).

0 ethos de "virtude" é projetado na medida em que o político mostra impressões de sinceridade na vida pública e privada; de transparência, quando diz não ter nada a esconder; de fidelidade para com as expectativas dos cidadãos; de honestidade pessoal, quando diz que busca honrar seus compromissos; de convicção aos ideais políticos que defende, ao afirmar que segue a mesma linha de pensamento e de ação; de lealdade, quando fala que respeita as críticas do adversário, que reconhece a validade do seu julgamento; de respeito para com os cidadãos, demonstrando ser direto, sem embustes. 0 político que deseja construir essa imagem deve atender a condição de performance, isto é, a capacidade de realizar o que promete (CHARAUDEAU, 2015).

O ethos de "competência" é evidenciado quando o político demonstra possuir um saber que o torna apto ao cargo que exerce, e a habilidade para realizar seus projetos de maneira eficaz. 0 orador mostra tais traços quando fala de seu percurso e experiência políticos, seja pela herança, por estudo, seja por funções exercidas anteriormente. Nesse sentido, o político que busca construir esse ethos, em seu discurso, deve atender a condição de eficácia, isto é, agir de modo que os resultados do que foi prometido serão positivos no decorrer de seu mandato político (CHARAUDEAU, 2015).

\subsection{Ethé de identificação}

0 ethos de "potência" é construído pela demonstração de energia física, de disposição e de determinação do político para trabalhar; pela vociferação, inclusive por insultos dirigidos aos adversários; pela exaltação do corpo como prova de verdade; pelas proezas físicas, realizadas de maneira coordenada, quase militar ou esportiva; pelas encenações de força, pela voz e pelo verbo (CHARAUDEAU, 2015).

0 ethos de "caráter" está associado à força interior, do "espírito"; à vituperação forte, mas controlada, quando se faz críticas; à força tranquila, pela qual o político demonstra serenidade, controle e equilíbrio de si, que pensa antes de agir; à provocação, quando se busca impulsionar uma ação daquele que é provocado; à polêmica, percebida nos conflitos políticos e nos insultos; à coragem, 
evidenciada no modo pelo qual o sujeito político é capaz de enfrentar situações conflituosas e não se curvar perante os discursos demagógicos; ao orgulho, quando o político mostra uma ambição de realizar projetos e obras grandiosos, e de defender os valores e a identidade do povo; à moderação, quando o político procura gerir e temperar suas ações para mediar e negociar acordos entre as partes em situações conflituosas (CHARAUDEAU, 2015).

O ethos de "inteligência" pode ser projetado quando o político fizer referência à sua formação e títulos acadêmicos; ao arcabouço artístico e cultural que ele herdou de sua origem social; aos livros que escreveu; e ainda, quando ele se mostra malicioso, isto é, capaz de saber fingir ou mascarar as suas intenções e pretensões políticas diante dos oponentes, das mídias, para que seus objetivos possam ser alcançados (CHARAUDEAU, 2015).

O ethos de "humanidade" é percebido pelo sentimento, angústia e compaixão do político, mas somente diante das dificuldades e necessidades que outros enfrentam, principalmente os mais pobres, e de datas históricas, como o dia da independência, acontecimentos trágicos, exaltação de heróis de guerra; pela sua capacidade de encontrar soluções para os problemas daqueles que são menos favorecidos; por mostrar alteridade e empatia; por confessar e reconhecer suas fraquezas, seus erros, ora dizendo que não agiu suficientemente para resolver uma situação de crise ou que ninguém teria feito melhor, desmontando as críticas adversárias, ora fazendo declarações a respeito de sua atividade política passada, na qual pode revelar não ter tido êxito em todas as suas empreitadas, por cálculos equivocados, mesmo com uma certa lógica (CHARAUDEAU, 2015).
0 ethos de "chefe" pode ser evidenciado quando o político busca apresentar-se como um líder que sabe o caminho a ser seguido para alcançar o bem da coletividade; como uma voz (sobrenatural, inspirada) que indica o caminho de salvação eterna, que é capaz de guiar o povo em meio às peripécias do mundo; como soberano, quando profere discursos que lembram valores e princípios fundamentais, de modo a encarnar-se neles, a saber, democracia, soberania do povo, identidade nacional; como aquele que sempre toma uma posição acima do conflito, não se envolvendo em polêmicas, nem em pequenas querelas politiqueiras ou não se comprometendo com vãs controvérsias; como comandante, para mostrar uma imagem do senhor da guerra, daquele que tem autoridade para declarar guerras em suas fronteiras; como aquele que é capaz de distinguir entre o bem e o mal, e, ao dizer-se esclarecido por uma força transcendente ou sobrenatural, indicar a via que segue para combater as forças do mal; como uma pessoa que está destinada a arrastar todo um povo atrás de si em direção à sua salvação (CHARAUDEAU, 2015).

O ethos de "solidariedade" é construído pelo político que demonstra ter sentimento para se colocar no lugar daqueles que estão em dificuldade, de estar junto deles; que assume a responsabilidade de resolver os problemas sociais; que partilha e defende as mesmas ideias e pontos de vista de seu grupo; que mantém uma reciprocidade entre seus atos e declarações; que se associa a manifestações sociais; que esteja consciente das responsabilidades que cabem a si próprio e ao seu governo; que escuta a opinião pública; que se dispõe a estar atento aos problemas, aos sofrimentos e às necessidades dos administrados (CHARAUDEAU, 2015). 


\section{Aspectos metodológicos}

Para executarmos nosso principal objetivo, adotamos a abordagem de cunho qualitativo, tendo em vista que procuramos analisar o corpus da nossa pesquisa, com base nas interpretações e reflexões suscitadas em nossa teoria de base (AMOSSY, 2013; CHARAUDEAU, 2015; MAINGUENEAU, 2008, 2011, 2013).

O corpus da pesquisa é constituído pela mensagem que o presidente da Guiné-Bissau José Mario Vaz dirige à nação e aos parlamentares que integram a Assembleia Nacional Popular (ANP), a despeito da situação de tensão e crise política entre os órgãos de soberania governamental. Tal mensagem foi proferida no ano de 2015, como uma resposta oficial aos rumores que circulavam sobre a possível queda de governo chefiado pelo primeiro-ministro Domingos Simões Pereira, acusado de nepotismo e corrupção. Segundo o próprio Jomav disse na época, essa mensagem visava estancar os boatos e conclamar os cidadãos ao trabalho. Ele confessou também que as relações entre os órgãos de soberania nacional poderiam ser melhores, e que foi muito cauteloso no modo de lidar com essa situação, pois tinha poder político para tomar decisões autoritárias. 0 pronunciamento ocorreu na Assembleia Nacional Popular (ANP), logo após a votação de moção de confiança dos parlamentares em favor do primeiro-ministro. Nesse ínterim, Jomav já havia acusado outros membros do governo envolvidos em atos ilícitos e corruptos, mas que não sofreram nenhum tipo de sanção, devido à imunidade parlamentar.

A análise desse discurso político centrarse-á nos ethé de credibilidade e dos ethé de identificação, já que intentamos aplicar as categorias de ethos propostas por Charaudeau (2015). Em relação às característi- cas verbais, ainda que o autor não admita que "existam marcas específicas do ethos" (CHARAUDEAU, 2015, p. 118), procuramos evidenciar determinados elementos linguísticos que tenham relação com o modelo proposto. Depois faremos as interpretações e uma discussão teórica, com o intuito de compreender a maneira pela qual os ethé foram construídos, bem como compreender as possíveis implicações sociopolíticas, subjacentes a tais construções, no contexto político instável da Guiné-Bissau.

Tivemos acesso ao discurso político em que o presidente fala à nação e aos deputados no jornal online "O democrata GB"2. Esse documento pode não ser exatamente fiel ao que foi dito na íntegra porque foi reeditado por Sambú (2015), embora isso não seja prejudicial à análise. Cabe destacar a dificuldade de acesso a documentos oficiais cedidos pelos órgãos governamentais de GuinéBissau, tendo em vista que não encontramos nenhum portal digital que arquive ou registre em notas taquigráficas os discursos dos presidentes, ministros ou parlamentares.

\section{Análise dos ethé de credibilidade e de identificação de Jomav}

No início de sua mensagem, Jomav relembra alguns dos princípios que jurou respeitar, defender e cumprir, tais como a Constituição da República, as leis, a unidade nacional, quando foi eleito presidente de Guiné-Bissau, em 2014, conforme se lê a seguir.

[...] jurei por minha honra respeitar e defender a Constituição da República, bem como as Leis, a Independência e a Unidade Nacional. Jurei também dedicar a minha inteligência e as minhas energias ao serviço do Povo guineense, cumprindo com total fidelidade

2 Disponível em: http://www.odemocratagb. $\mathrm{com} / \mathrm{p}=5393$ 
os deveres da alta função que o povo me confiou (SAMBÚ, 2015).

0 ato de listar seus compromissos logo no começo de sua fala é uma maneira de atenuar as circunstâncias de crise pelas quais ele foi motivado a se pronunciar. Na verdade, mesmo que uma das causas da instabilidade política tenha sido provocada em seu mandato, Jomav continua convicto dos ideais políticos que defende, dedicando-se, com sua inteligência, energia, e total fidelidade, a cumprir tais responsabilidades para com o povo guineense. Isso significa que, após 1 (ano) de sua posse presidencial, ele continua a seguir a mesma linha de pensamento e de ação, inspirada nos valores, nem discutíveis nem negociáveis, que estão na base de seu projeto político. Por essas razões, ele constrói de si um ethos de "virtude".

No trecho abaixo, por conseguinte, nota-se a projeção do ethos de "solidariedade", haja vista que o presidente mostra-se consciente das responsabilidades que cabem a si, ao seu governo, e demonstra estar atento ao clamor e as necessidades do povo ("é perfeitamente audível"), a saber, pela paz política, institucional, social e da alma.

É perfeitamente audível que os guineenses clamam - e a meu ver, muito justamente por uma verdadeira e efectiva paz, não só política, institucional e social, como também das almas. Nisso reside o interesse nacional, cuja boa interpretação e satisfação compete a todos (SAMBÚ, 2015).

A construção da solidariedade pode estar associada ao desejo comum de todos os guineenses por estabilidade política, que não foi alcançada desde a independência do país na década de 1970. Esse é um dos valores de interesse nacional a ser atingido e preservado no mandato de Jomav, em um contexto político-social desfavorável. A imagem de solidário é verificada também pelo fato de que o político respeita os problemas, o sofrimento, as necessidades, dos seus compatriotas, e ainda, partilha com o povo essa situação de desconforto, devido ao impasse que se vive entre os seus máximos representantes.

Em outro momento de sua mensagem, Jomav desvela uma imagem de "sério', quando relembra suas promessas de governo, tais como trabalho, justiça, rigor, probidade na gestão da coisa pública.

[...] se bem me lembro também prometi trabalho, justiça, rigor e probidade na gestão da coisa pública. Para que não restem dúvidas, as minhas promessas não são meras retóricas eleitorais, mas sim para serem cumpridas (SAMBÚ, 2015).

Conforme salienta Charaudeau (2015), esse ethos é constituído quando o político faz promessas que exprimem justa medida, isto é, são adequadas e possíveis de serem executadas e cumpridas de maneira eficaz, mostrando que ele preocupa-se com o bem público de maneira realista.

Após reafirmar seus deveres de presidente da República, Jomav cita as especulações que circulavam sobre a possível queda de governo chefiado pelo primeiro-ministro Domingos Simões Pereira, acusado de nepotismo e corrupção. Interessante perceber que, diante de tal situação, ele diz que observou tudo com serenidade, com a natural compreensão, e que não se pronunciou sobre a queda do governo. É o que se lê no fragmento abaixo.

[...] muitas coisas foram ditas. Tantas especulações foram feitas. Muitas insinuações são lançadas minuto a minuto, todos os dias. 0 Presidente da República observou tudo com serenidade e com a natural compreensão que se impõe num contexto democrático. [...] O Presidente da República não se move por rumores, especulações e nem tão pouco em insinuações. Em nenhum momento, o Pre- 
sidente da República pronunciou-se sobre a queda ou não do Governo (SAMBÚ, 2015).

Nessa parte de sua mensagem, podemos verificar a construção do ethos de "caráter", haja vista Jomav demonstra uma serenidade natural, uma força tranquila, um controle de si, embora esteja inserido em um contexto desfavorável, de especulações contra ele, pela força tranquila e controle de si. A complementação de sua fala é seguida pela projeção do ethos de "chefe", quando diz que não se move por rumores ou que não se pronunciou sobre as insinuações, o que, conforme Charaudeau (2015), deixa entrever que ele toma uma posição acima de tudo que pode parecer conflitos estéreis, mostrando que não entra no jogo de pequenas querelas politiqueiras, que se recusa a polemizar quando é diretamente implicado, de maneira a se dar uma estatura de sujeito que domina a cena política, que não se rebaixa ao nível de agitadores, que não se compromete em vãs controvérsias.

Na sequência de seu discurso, o presidente lança uma solução viável para os problemas ocasionados pela instabilidade e crise políticas, qual seja: o trabalho.

Só com trabalho podemos alcançar a autosuficiência alimentar, reduzir o desemprego dos jovens, melhorar o nosso ensino, acudir as grávidas e jovens que vão morrendo diariamente nos nossos hospitais, as infra-estruturas, entre outros. [...] 0 trabalho sério e profissional é o único remédio contra festas, rumores, especulações e insinuações, que só servem para desviar a nossa atenção dos problemas de fundo como a corrupção, a delapidação de bens públicos, o nepotismo, o conflito de interesses, males que minam a credibilidade das nossas instituições, desvirtuam os valores da nossa sociedade, desencorajam a pro-actividade de investidores sérios, entre outros que graçam entre nós (SAMBÚ, 2015).
Nota-se que Jomav descreve as diversas vantagens do trabalho profissional, tais como a autossuficiência alimentar, a redução do desemprego, a melhoria no ensino e na infraestrutura, além de ser uma forma decente de combater os rumores propagados para fins de manipulação, para desviar a atenção da população dos males que minam a credibilidade das instituições e desvirtuam os valores da sociedade (corrupção, delapidação de bens públicos, nepotismo, conflito de interesses). Ao fazer isso, o presidente produz um ethos de "competência", porque demonstra ter conhecimento do universo político no qual exerce seu mandato, e lança mão de um meio ("o trabalho") para realizar e alcançar objetivos que beneficiem a coletividade, que é a estabilidade política.

Na sequência, lê-se a parte da mensagem na qual o chefe de Estado se refere ao seu percurso político, desde que assumiu "o compromisso de servir aos outros".

Desde que assumi o compromisso de servir os outros, a começar pela minha passagem pela Câmara de Comércio, Câmara Municipal de Bissau e Ministério das Finanças, trabalhei e trabalho todos os dias imbuído do espírito de verem materializadas as expectativas legítimas da nossa população, nomeadamente a melhoria da sua condição de vida. [...] A título de exemplo, cito a nossa contribuição na mobilização do empréstimo de quinze bilhões de Francos CFA logo após a instalação do Governo. [...] Igualmente, participei pessoalmente [...] na Mesa Redonda realizada em Bruxelas em Março de 2015, para reforçar e dar maior dimensão político -institucional e diplomática à iniciativa do Governo da República da Guiné-Bissau, [...] não deixei de participar nos fóruns regionais da CEDEAO e da UEMOA. [...] Quero assegurar-vos que, como tenho feito até aqui, estarei sempre disponível em apoiar todas as iniciativas do Governo que visem encontrar os meios para materializar o seu programa 
de desenvolvimento económico e social. (SAMBÚ, 2015).

As funções que o orador assumiu foram voltadas para contribuir com o desenvolvimento nacional, para melhorar a imagem de Guiné-Bissau no contexto mundial, e para a melhoria da condição de vida da população guineense. Como exemplificação, ele lista algumas de suas realizações, como a mobilização de empréstimos através de parcerias, de uma política externa, de participações em eventos diplomáticos. Assim, ao demonstrar que possui um saber que o torna apto ao cargo que exerce, e a habilidade para realizar seus projetos de maneira eficaz, comprovados quando fala de seu percurso e experiência políticos, Jomav constrói novamente um ethos de "competência". E ainda, essa imagem é verificada quando ele ressalta que sempre vai estar disponível em todas as iniciativas do Governo para fazer Guiné-Bissau se desenvolver, na medida em que o político, por sua experiência em funções públicas, tem o que é preciso para agir de modo que os resultados do que foi prometido serão positivos no decorrer de seu mandato político.

0 presidente, em outro momento de sua fala, reivindica ações efetivas e comprometimento dos representantes políticos para buscar soluções que criem e garantam condições de uma verdadeira estabilidade governativa.

É verdade que esforço de afirmação, a necessidade de visibilidade política, o empenho na delimitação de áreas de competências exclusivas por alguns de nós não tem produzido efeitos convergentes com os propósitos iniciais de estabilidade política das nossas instituições. Para que esses propósitos iniciais possam perdurar até ao fim da legislatura, como é nosso profundo desejo, temos que abandonar as nossas zonas de conforto formal e buscar soluções de compromisso que criem e garantam condições de uma verdadeira estabilidade governativa (SAMBÚ, 2015).

Por tais reivindicações, Jomav constrói um ethos de "caráter", ao mesmo tempo que demonstra energia, tenacidade e determinação para alcançar o principal objetivo de seu governo, que é a estabilidade política. Essa vontade de vencer, de enfrentar as adversidades sem enfraquecer, é um aspecto que reforça a projeção dessa imagem no excerto acima.

Já o fragmento a seguir atesta a produção do ethos de "chefe", pois Jomav compara a sua conduta a de um comandante de um navio, que está sempre atento para guiar os guineenses rumo à estabilidade e ao desenvolvimento da nação ("o bom porto"), e que sabe corrigir a desatenção da tripulação.

[...] o espírito que molda a nossa conduta é a de um comandante atento aos movimentos do leme e à direcção dos ventos, pronto a corrigir qualquer veleidade ou desatenção da tripulação para garantir uma navegação correcta, segura e o atracar do navio num bom porto (SAMBÚ, 2015).

De acordo com Charaudeau (2015), essa imagem é construída quando o político demonstra ter qualidades e atributos daquele que guia, que indica o caminho a ser seguido, que conduz e acompanha o povo, que sabe aonde vai e que é seguido. Ao comparar a nação a um navio, que ora navega por mares tranquilos, ora oscilantes e tortuosos, ele se coloca como o comandante, como o chefe.

$\mathrm{Na}$ parte final de seu discurso, o presidente relembra o exemplo de unidade e de luta daqueles que se empenharam na busca pela independência do país, como uma estratégia de argumentação para mostrar que a luta da nação não é mais pela libertação colonial, mas pela estabilidade política.

Hoje, todos nós nos revemos no exemplo dos nossos valorosos Combatentes da Liberdade da Pátria e sentimo-nos orgulhosos da his- 
tória da Luta de Libertação Nacional, cujo exemplo maior de UNIDADE e LUTA constitui uma base sólida sobre a qual devemos apoiar-nos na difícil e sempre inacabada tarefa de construir uma Nação estável, próspera e de gente digna, em consonância com ideais de Luta de Libertação Nacional (SAMBÚ, 2015).

Sob essa perspectiva, Jomav projeta um ethos de "humanidade", pois, ao relembrar um feito histórico significativo para a nação, que é a independência nacional, bem como exaltar os heróis que estiveram à frente dessa conquista, ele demonstra angústia diante das dificuldades e necessidades que Guiné-Bissau enfrenta há mais de 40 anos. 0 exemplo dos antepassados é uma maneira de encorajar os representantes políticos e o povo a constituir uma base sólida, com a finalidade de construir uma nação estável, próspera e de gente digna, em consonância com ideais de luta de libertação nacional.

Jomav termina seu pronunciamento conclamando aqueles que têm o dever de combater pelo desenvolvimento nacional, como se lê abaixo.

Mais do que nunca, o nosso destino está nas nossas próprias mãos [...] pois, cabe sobretudo a nós, Combatentes pelo Desenvolvimento Nacional, a responsabilidade de erguer este país das cinzas, resolver os nossos problemas, respeitando-nos mutuamente e, sobretudo, falando verdade (SAMBÚ, 2015).

0 político também reivindica uma ação efetiva na tentativa de erguer o país das cinzas, de resolver os problemas e crises políticos, ao mesmo tempo em que demonstra energia e determinação para tal finalidade. Nota-se ainda que Jomav projeta-se como aquele que não abandona seus compromissos, que tem vontade de alcançar os objetivos que planeja. Essas são as características do ethos de "caráter", o qual é construído pelo presidente nessa parte final de seu discurso.

\section{Considerações finais}

Essa pesquisa desvelou que José Mário Vaz constrói imagens de si ora de credibilidade, ora de identificação como uma estratégia política com o intuito de atenuar as circunstâncias de tensão política e de incompatibilidades na relação entre presidente da República e o Primeiro Ministro, bem como para ressaltar a legitimidade das ações governamentais para resolver os problemas ocasionados pela instabilidade política de Guiné-Bissau.

Nesse sentido, os ethé de credibilidade, nomeadamente o ethos de "virtude", o de "sério', e o de "competência”, foram projetados por Jomav quando ele buscou mostrarse convicto dos ideais políticos que sempre defendeu; como político dedicado e comprometido; como conhecedor do contexto político no qual exerce seu mandato; como aquele que tem a habilidade para alcançar os objetivos que beneficiem a coletividade; como político experiente, ao falar de seu percurso político para provar sua aptidão no cargo que exerce.

Já os ethé de identificação, detidamente o de "solidariedade", o de "caráter", o de "chefe", e o de "humanidade", foram construídos na medida em que Jomav demonstrou que é um político consciente das responsabilidades que cabem a si, ao seu governo; como político atento ao clamor e às necessidades do povo; como pessoa serena, tranquila e que tem autocontrole, embora esteja inserido em um contexto de especulações contra si; como político que reivindica ações efetivas e comprometimento dos representantes políticos para buscar soluções que garantam a estabilidade econômica, política; como aquele que tem energia, tenacidade e determinação para realizar grandes obras em seu governo; como político que tem vontade de vencer, de enfrentar as adversidades sem en- 
fraquecer; como político que toma uma posição acima de tudo que pode parecer conflitos estéreis e controversos; como presidente angustiado para agir no intuito de resolver as dificuldades e necessidades do povo.

\section{Referências}

AMOSSY, Ruth. (org.). Imagens de si no discurso: a construção do ethos. São Paulo: Contexto, 2013.

ARAÚJO, Helmer (Org.). Guiné-Bissau. Brasília: Thesaurus Editora \& FUNAG, 2012.

ARCINE, Raquel F.; PASSETTI, Maria C. C. A construção do ethos de identificação de José Serra em seu discurso de pré-candidatura para a eleição presidencial brasileira de 2010. In: SEMINÁRIO NACIONAL EM ESTUDOS DA LINGUAGEM, 2010, Cascavel. Anais... Cascavel: UNIOESTE, 2010.

ARISTÓTELES. Retórica. Lisboa: Imprensa Nacional-Casa da Moeda, 2005.

AUGEL, Moema P. 0 desafio do escombro: nação, identidades e pós-colonialismo na literatura da Guiné-Bissau. Rio de Janeiro: Garamond, 2007.

BARTHES, Roland. L'aventure sémiologique. Paris: Editions du Seuil, 1985.

CHARAUDEAU, Patrick. Discurso político. São Paulo: Contexto, 2015.

FERRANTE, Audrei. Discurso político e ethos: os discursos de posse do prefeito de São Caetano do Sul. 2011. 190 f. Tese (Doutorado em Letras) - Programa de Pós-Graduação em Letras, São Paulo, 2011.

GANDIN, Lucas; PANKE, Luciana. A transferência de ethos de Lula para Dilma na campanha eleitoral de 2010. Revista Ciência Política, Paraná, v. 6, n. 1, p. 167-186, 2015.

IÉ, Nivaldo C.; LANGA, Ercílio N. B. Sistema político de governação na Guiné-Bissau (19912019). 2019. 26 f. Trabalho de Conclusão de Curso (Licenciatura em Ciências Sociais) - Instituto de Humanidades e Letras dos Malês, São Francisco do Conde-BA, 2019.

MAINGUENEAU, Dominique. A propósito do ethos. In: MOTTA, A. R. \& SALGADO, L. (Orgs). Ethos discursivo. São Paulo: Contexto, 2008. p.11-29.

MAINGUENEAU, Dominique. Análise de textos de comunicação. São Paulo: Cortez: 2011.

MAINGUENEAU, Dominique. Ethos, cenografia, incorporação. In: AMOSSY, Ruth. (Org). Imagens de si no discurso: a construção do ethos. São Paulo: Contexto, 2013. p. 69-91.

MAINGUENEAU, Dominique. Discurso e análise do discurso. São Paulo: Parábola Editorial, 2015.

MAINGUENEAU, Dominique. Retorno crítico à noção de ethos. Revista Let. Hoje, Rio Grande do Sul, v. 53, n. 3, p. 321-330, 2018.

MAINGUENEAU, Dominique. Variações sobre o ethos. São Paulo: Parábola, 2020.

M'BUNDE, Timóteo S. As políticas externas brasileira e chinesa para a Guiné-Bissau em abordagem comparada (1974-2014). Rio de Janeiro: Gramma, 2018.

MESTI, Paula C. Análise discursiva dos ethé de um sujeito político em campanha eleitoral. 2010. 150 f. Dissertação (Mestrado em Letras) - Programa de Pós-Graduação em Letras, Maringá-PR, 2010.

PITA, Sara; PINTO, Rosalice. Construção dos ethè em discursos políticos em Portugal e no Brasil: um estudo comparativo. Revista Redis, n. 3, p. 126-154, 2014.

SAMBÚ, Assana. Discurso na sua íntegra: Jomav afirma que em nenhum momento pronunciou-se sobre a queda ou não do governo. Jornal O democrata, Bissau, 2015. Disponível em: <https://bit.ly/39ljJFu> Acesso em: 26 jan. 2021.

TEIXEIRA, Dumas R. Cabo-Verde e Guiné-Bissau: as relações entre a sociedade civil e o estado. Recife: Ed. Do Autor, 2015.

TOMAZ, Natália R. O.; GOUVÊA, Lúcia H. M. Um estudo do ethos em discursos do ex-presidente Lula. Revista Estudos da Linguagem, Belo Horizonte, v. 25, n. 1, p. 441-471, 2017.

Recebido em: 22/03/2021 Aprovado em: 20/07/2021 